\title{
Working cheaper
}

I m no economist, but I think we are in for a seven-year bad stretch. However, there are glimmers of strength. Money is worth something again. Even so, hospitals are in crisis mode.

The bottom line is king and the budget is all. Last week, I heard we have to cut $5 \%$ to eliminate our annual projected hospital budget deficit - we have to meet our target or else.

Our waiting lists are getting longer. It is now a four-month wait to excise a basal cell carcinoma, which is a month longer than our guideline of 89 days. Let's be positive. Let's think like plastic surgeons. This is what we can do:

1. We can do more with less. We can do more surgery under local anaesthesia and concentrate on teaching anaesthesia, especially local and sedation techniques, to surgical trainees so they feel confident and patient safety is protected.

2. Those of us who run surgical clinics know what everything costs; those who work only in hospitals do not. We need to be unafraid to discuss costs with hospital staff every day so they understand these numbers and we need to practise frugality proudly. We need to show we are using that 50 nylon down to the very end, and we need to know what that suture and drug actually costs.

3. We can promote the use of minor surgery rooms in hospitals. These rooms are very efficient, and require only one nurse, one volunteer and one surgeon to run. Patients love them particularly if surgery is painless, and they can eat and drive before and after surgery.

4. However, there are a lot of obstacles to do this. Surgeons need to believe they actually can do a good carpal tunnel release under local without a tourniquet. We have to get over our training and do things we were not taught to do and in some cases do things we were taught not to do. Exciting!

5. Operating rooms can be more efficient. We can do this by effective communication with the team and by creating a positive atmosphere by not over-booking. We need to enjoy surgery quietly. "Let's talk about that later" is a good phrase.

6. Lunch breaks in the middle of an operating day should be eliminated no matter what the union says. There is no good reason to stop an expensive operating room in the middle of the day just to have lunch. If you want to work in the operating room, have a sandwich in the lunch room next to the operating room between cases, and move ahead. Put the patient first and your lunch second. If the surgeon can work through, so can the nurses. Breaks should be for fluid requirements (in and out).

7. There are things we should not cut. There are those who want us to operate without preoperative tests. Sounds good to someone with no experience. As for me, I want the basic tests: complete blood count, platelets, international normalized ratio, electrolytes and an electrocardiogram. I don't like surprises and these tests are inexpensive considering what happens when you get blind-

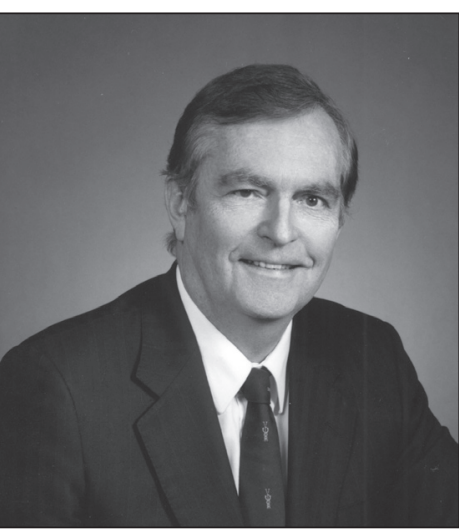
sided by a low plate-

let count or high international normalized ratio in someone not at risk.

8. Good instruments actually save money but they have to be treated like the fine products they are. Needle drivers will last 'forever' if they are excellent quality to start with and are not crunched down to the final ratchet. Scissors will too and never need sharpening if used carefully.

So:

Thinking outside the box is difficult in a world full of boxes, but if anyone can do it, plastic surgeons can.

The hard part is selling change when others like their boxes.

Catch 22 (there's always a catch 22). If you know you are insane, you can't be insane, so you can't get out of the air force (Joseph Heller).

We surgeons can always think of ways to do more surgery. The trouble is, we are surrounded by people who don't want to do more surgery - they want to finish the day and go home. So these people, some of whom we love dearly, can dream up lots of objections to doing more surgery (the blood sugar isn't done, you can't finish on time, you can't use more local time, what will the anaesthetists do if you work under local, I'm not trained to monitor the patient, that is the anaesthetist's job, and the dreaded one: you forgot the pause). Heavens to Betsy!

So, if you want to do more surgery, you must be insane. But if you know you are insane, you can't be insane.

You figure it out. As for me, I'm going home and let greater minds deliberate.

It won't be long before we are trading ration cards.

I'll trade you a carpal tunnel for a basal cell?

So long inmates: To get out of your box just open the door. 